\title{
Learning in cod (Gadus morhua): long trace interval retention
}

\author{
Jonatan Nilsson • Tore S. Kristiansen • \\ Jan Erik Fosseidengen • Anders Fernö • \\ Ruud van den Bos
}

Received: 21 March 2007 / Revised: 2 July 2007 / Accepted: 3 July 2007 / Published online: 24 July 2007

(C) Springer-Verlag 2007

\begin{abstract}
Basic knowledge about learning capacities and awareness in fish is lacking. In this study we investigated which temporal gaps Atlantic cod could tolerate between two associated events, using an appetitive trace-conditioning paradigm with blinking light as conditioned stimulus (CS) and dry fish food as unconditioned stimulus (US). CS-US presentations were either temporally overlapping (delay conditioning, CS duration $24 \mathrm{~s}$, interstimulus interval $12 \mathrm{~s}$ ) or separated by 20,60 , or $120 \mathrm{~s}$ (trace conditioning, CS duration $12 \mathrm{~s}$ ) or $2 \mathrm{~h}$ (control, CS duration $12 \mathrm{~s}$ ). The percentage of fish in the feeding area increased strongly during CS presentation in all delay, $20 \mathrm{~s}$, and $60 \mathrm{~s}$ trace groups and in one out of two $120 \mathrm{~s}$ trace groups, but not in the control groups. In the 20 and $60 \mathrm{~s}$ trace procedures, the fish crowded together in the small feeding area during the trace interval, showing strong anticipatory behaviour. In all the conditioned groups, the fish responded to the CS within eight trials, demonstrating rapid learning. At 88 and 70 days after the end of the conditioning experiments, the delay and $20 \mathrm{~s}$ trace groups, respectively, were presented the CS six times at 2-h intervals without reward. All groups responded to the light signal, demonstrating memory retention after at least 3 months. This study demonstrates that Atlantic cod has an impressively good
\end{abstract}

J. Nilsson $(\bowtie) \cdot$ T. S. Kristiansen · J. E. Fosseidengen Institute of Marine Research, 5392 Storeb $\varnothing$, Norway

e-mail: jonatan.nilsson@imr.no

A. Fernö

Department of Biology, University of Bergen,

P.O. Box 7800, 5020 Bergen, Norway

R. van den Bos

Department of Animals, Science and Society,

Utrecht University, Yalelaan 2, 3584,

CM Utrecht, The Netherlands ability to associate two time-separated events and long time retention of learnt associations.

Keywords Trace conditioning $\cdot$ Memory $\cdot$ Fish

\section{Introduction}

In the course of the past decade, rising interest in the cognitive capacities of fish has revealed that their learning capacities are greater than popularly believed (Laland et al. 2003; Brown et al. 2006), and that fish demonstrate a developmental stage suggestive of sentience (Chandroo et al. 2004). During the last few years it has become evident that fish have lateralized brains, i.e. left-right perceptual asymmetries, a characteristic that has long been considered unique to the human species (Sovrano et al. 1999; Vallortigara and Rogers 2005). Learning plays a significant role in several aspects of fish behaviour, such as social interactions (Brown and Laland 2003), foraging (Warburton 2003), antipredator behaviour (Kelley and Magurran 2003) and orientation (Odling-Smee and Braithwaite 2003). Recent investigations have shown that fish can combine geometric and nongeometric information to reorient themselves, an ability not found in human infants and rats (Sovrano et al. 2002, 2007). However, while most studies of fish learning have dealt with learning in specific situations, such as improvement of foraging or predator-avoidance skills, surprisingly little has been done to reveal fundamental learning capacities. Basic questions like "how far can events that are separated in time still be associated?" or "for how long can fish remember once learnt associations?" are still largely unanswered.

The ability to associate events is essential to modify behaviour in a changing environment, where animals 
encounter a multitude of sensory information in their everyday life, i.e. which event predicts the next. Events such as the sight of a predator and an attack often overlap in time. However, such events may also be separated in time, in that an event is preceded by a cue that does not persist until the event takes place. For instance, the sight of fleeing individuals may indicate that a predator is likely to appear in the very near future.

Associative learning occurs when an association between two events is established. In Pavlovian (classical) conditioning a neutral stimulus (conditioned stimulus, CS) is repeatedly paired with and precedes an aversive or hedonic stimulus that elicits a response without training (unconditioned stimulus, US). When an association is established, the CS elicits a response similar to the response elicited by the US. To learn an association between stimuli separated by a temporal gap (trace conditioning) is more demanding than when stimuli are overlapping in time (delay conditioning; Lieberman 2000). Trace conditioning is also dependent on more advanced brain functions. While both delay and trace conditioning are dependent on the cerebellum (Thompson and Kim 1996), trace conditioning is also reliant on hippocampal functions in land vertebrates (Solomon et al. 1986; Thompson and Kim 1996) and in teleosts on the lateral pallium, which is believed to be a homologous and functional equivalent to the hippocampus (Braford 1995; Butler 2000; Portavella et al. 2002, 2004). It is well known that fish can easily be conditioned to associate a CS with a US (Bull 1928; Overmier and Hollis 1990). However, the capacities of trace conditioning in fish have been poorly investigated, and the experiments that have been done have used trace intervals of only a few seconds duration, often to investigate brain functions rather than learning capacities per se (e.g. Overmier and Savage 1974; Portavella et al. 2004). To the best of our knowledge, no work has investigated how long time gaps between two events fish are able to bridge, and such investigations are surprisingly sparse for other taxa as well.

When something is being learnt, it must be remembered for some length of time. Although the period of memory can be dependent on ecological context and may vary between populations (Mackney and Hughes 1995; Brown and Braithwaite 2005), memories in fish may in some circumstances persist for a substantial period. Paradise fish (Macropodus opercularis) can recognize another species 3 months after the first encounter (Csányi et al. 1989). Carp (Cyprinus carpio) captured by angling are more difficult to catch a year after a single hooking than individuals that did not have the angling experience (Beukema 1970), and in rainbowfish (Melanotaenia duboulayi) that have learnt to avoid a trawl apparatus in the laboratory the avoidance persists for at least 11 months (Brown 2001). To remember and hence increase the probability of responding correctly to reward-related cues should indeed be beneficial, but there are few investigations on fish's ability to retain positive memories over a long time period.

Atlantic cod (Gadus morhua) has been shown to be able to associate different stimuli. Delay conditioning (aversive) to sound signals was used by Chapman and Hawkins (1973) to investigate the hearing thresholds of cod. Midling et al. (1987) found that juvenile cod kept in a large net-pen easily learnt to associate a low frequency sound signal with food in a delay conditioning procedure, and the fish approached the sound source from at least $400 \mathrm{~m}$ distance after being released in the sea. Cod also learnt to treat baited hooks more carefully after only one aversive experience (Fernö and Huse 1983), and to associate ingestion of poisoned food with illness (MacKay 1974). Reared cod have also been shown to improve their anti-predator behaviour and foraging of new prey items through learning (Fernö et al. 2006 and references within). However, systematic studies of the ability of cod to associate events are lacking.

The aim of this study was to investigate whether cod had the capacities for long-trace conditioning, and to find the limits for temporal separation of two associated events. This was done using an appetitive trace-conditioning paradigm where the conditioned and the unconditioned stimuli were separated from overlap to $120 \mathrm{~s}$. We also looked at whether the memory of the learnt CS-US association persisted over long time periods.

\section{Methods}

Experimental set-up

Experiments were performed in March-April 2004 and May-June 2005. Indoor circular tanks of $3 \mathrm{~m}$ diameter and $1 \mathrm{~m}$ depth were filled with about $70 \mathrm{~cm}$ seawater at $7-9^{\circ} \mathrm{C}$ with $\mathrm{O}_{2}$ saturation above $90 \%$. The water flow was $501 \mathrm{~min}^{-1}$ in 2004 and $751 \mathrm{~min}^{-1}$ in 2005 . The illumination period was $24 \mathrm{~h}$ with a mean intensity of $1.14 \mathrm{uE} \mathrm{m}^{-2}$ $\mathrm{s}^{-1}$ (60 Lux), measured midwater. A floating, $50 \mathrm{~cm}$ diameter ring of transparent tubing, containing a chain of 40 small $2.4 \mathrm{~W}$ light bulbs (total effect $96 \mathrm{~W}$ ), was placed under the automatic feeder near the wall of each tank, allowing the food to drop into the ring (Fig. 1). The behaviour of the fish was recorded by a video camera hanging $2.5 \mathrm{~m}$ above each tank.

\section{Subject fish}

The cod were hatched from naturally fertilized eggs from wild-caught brood stock from a mixed population of coastal cod (Dahle et al. 2006). After hatching in March the year 


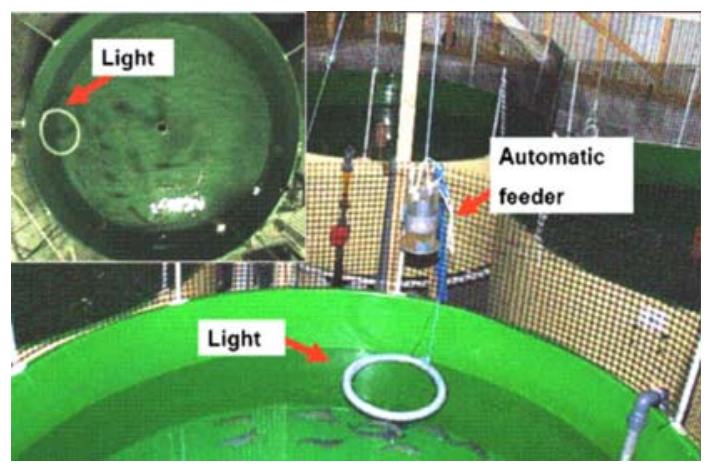

Fig. 1 The experimental tank. The feeder was located above the CS ring, so that the CS and the US spatially overlapped

before the experiment started the larvae were reared semiintensively in floating bags on natural zooplankton, and later weaned to dry food. The following autumn the fish were transferred to sea-cages and fed on marine dry food. Ten to 27 days in advance of the experiments 15 fish were transferred to each of the experimental tanks for acclimation. No experiment started until the fish showed no signs of stress and responded well to offered food. The light ring was in the tank all the time but was never switched on before the first learning trial. In order to minimize stress prior to the experiment the lengths and weights of the fish were not recorded until after the end of the conditioning experiment. These ranged from $28-41 \mathrm{~cm}$ and $250-800 \mathrm{~g}$ (mean 2004: $32 \mathrm{~cm}, 380 \mathrm{~g}$; mean 2005: $35 \mathrm{~cm}, 520 \mathrm{~g}$ ).

\section{Experimental procedure}

\section{Conditioning experiment}

The CS was a series of light blinks (about $0.8 \mathrm{~s}$ on and $2 \mathrm{~s}$ off) from the ring. The US was sinking marine fish pellets (Skretting, Europa), $3 \mathrm{~mm}$ in 2004 and $7 \mathrm{~mm}$ in 2005. In order to avoid satiation and hence loss of learning motivation, the amount of food given per day was $0.5 \%$ of the estimated biomass, about $2 / 3$ of the satiation ratio of cod of this size at these temperatures. The fish were fed every 4 th hour, i.e. six trials per day, with each feeding session lasting $1 \mathrm{~min}$. In the delay experiment the duration of the CS was $24 \mathrm{~s}, 12 \mathrm{~s}$ of which overlapped with the US (interstimulus interval $=12 \mathrm{~s}$ ) in order to ensure that the CS continued until the fish had detected and responded to the US. In all the trace and control experiments the duration of the CS was $12 \mathrm{~s}$. Three different trace intervals were employed: $20 \mathrm{~s}\left(\mathrm{~T}_{20}\right), 60 \mathrm{~s}\left(\mathrm{~T}_{60}\right)$ and $120 \mathrm{~s}\left(\mathrm{~T}_{120}\right)$. In the unpaired control experiment the CS-US interval was $2 \mathrm{~h}$. Each procedure was carried out in parallel, in two tanks, each containing 15 fish. The delay, $\mathrm{T}_{20}$, and control experiments were carried out in 2004 and $\mathrm{T}_{60}$ and $\mathrm{T}_{120}$ in 2005. In the delay and trace experiments trials were recorded from 5 $6 \mathrm{~min}$ before to $3 \mathrm{~min}$ after the end of the feeding session, and stored on DVD for later analysis. In the control experiments CS and US trials were recorded separately. As learning was assumed to be slower at longer trace durations, the $120 \mathrm{~s}$ trace experiments comprised more trials (64) than the delay, $\mathrm{T}_{20}, \mathrm{~T}_{60}(52)$ and control experiments (53).

Memory test

After the end of the experiments in 2004 the delay-conditioned and $20 \mathrm{~s}$ trace-conditioned fish were transferred to two separate $1.5 \mathrm{~m}$ diameter tanks in order to isolate the fish from the CS and the environment in which they had been trained. The fish from one of the replicates of each treatment were anaesthetised with benzocaine $(10 \mathrm{~g}$ in $100 \mathrm{ml} 96 \%$ ethanol; $5 \mathrm{ml}$ benzocaine solution per 101 oxygenated sea water; fish were kept for 3-5 min until immobilisation) and tagged (Floy FD68BC anchor tags) to identify the fish from different replicates. Tagging was done by means of a hollow-needle tagging-gun (Dell 1968). The anchor tags were put on the left of the fish in front of the first dorsal fin so that they engaged the dorsal pterygiophores. Previous studies have shown that anchor tags have no effects on growth and mortality in cod (Otterå et al. 1998). The tanks were supplied by the same water source as in the conditioning experiments and continuously lit. The fish were fed 3 days a week with the same food as earlier (average ration $0.5 \% \mathrm{~d}^{-1}$ ). After 87 days for the delay fish and 69 days for the $\mathrm{T}_{20}$ fish, the tagged and untagged groups were separated into the original groups and transferred back to the tanks in the learning laboratory and acclimated for $30 \mathrm{~h}$ before the memory test. During the isolation period the total mortality was $15 \%$ ( 9 fish, 1 and 2 in the delay groups, 1 and 5 in the $T_{20}$ groups), and the numbers of fish were therefore somewhat lower in the memory tests than in the conditioning experiments. Before testing the fish were fed a small ration of pellet to ensure that they were motivated to feed. The memory test consisted of giving the fish a CS of $12 \mathrm{~s}$ repeated six times at two- (on one occasion three-) hour intervals without reward. The responses to the CS were recorded by camera and stored on DVD.

Video analysis

The DVD recordings were analysed using InterVideo Win DVD software. In order to see how the fish responded to a novel light signal every trial was analysed early in the experiment (first six-eight trials). Later every second trial was analysed and from trial 11 or 12, every fourth trial was analysed (except for trial 40 in the delay groups which was not stored on DVD). At the end of the experiment trials were analysed at shorter intervals, in order to place emphasis 
on the part of the experiment where the fish were most likely to have become conditioned. All the analysed trials are shown in Fig. 2. During analysis the image of the tank was divided into four equal $90^{\circ}$ sections with the light ring placed in the centre of one section (CS/US section). The number of fish in each section was recorded on frozen images at three sampling points each for three or four intratrial periods:

Baseline: (120, 60 and $5 \mathrm{~s}$ prior to onset of the CS)

CS: (at 5, 8 and $12 \mathrm{~s}$ after onset of the CS)

Trace: (in the trace experiments; at $1 / 4,2 / 3$ and $1 / 1$ of the total trace duration)

US: (at 10, 32 and $60 \mathrm{~s}$ after onset of the US)
The average score of the three time points of each intra-trial period was converted to a percentage of the total number of individuals. In the memory test, the percentages of fish in the CS section during baseline and CS were sampled in the same manner.

\section{Statistics}

With the prediction that the fish would approach the CS/US section at the onset of the CS if they associated the CS with the US, the proportion of fish in the CS/US section should be higher during the CS than before CS onset (baseline). This was tested with a one-tailed Wilcoxon signed rank test
Fig. 2 Percentage of fish in the CS/US section of the tank before CS onset (baseline, open squares), during the CS (filled circles), the trace interval (filled triangles) and the US (open triangles) throughout the experiment. $P$ values are given by the Wilcoxon signed rank test of the hypothesis that the percentage of fish in the CS/US section is higher during the CS than before CS onset. $N$ is the number of trials included in the test. The trials included in the test are marked out. $B a r$ at the $x$-axis indicates the range of trials in which a CS-US association has occurred with 95\% probability. Left (replicate 1) and right (replicate 2) figures are replicate groups. Each group contained 15 individuals
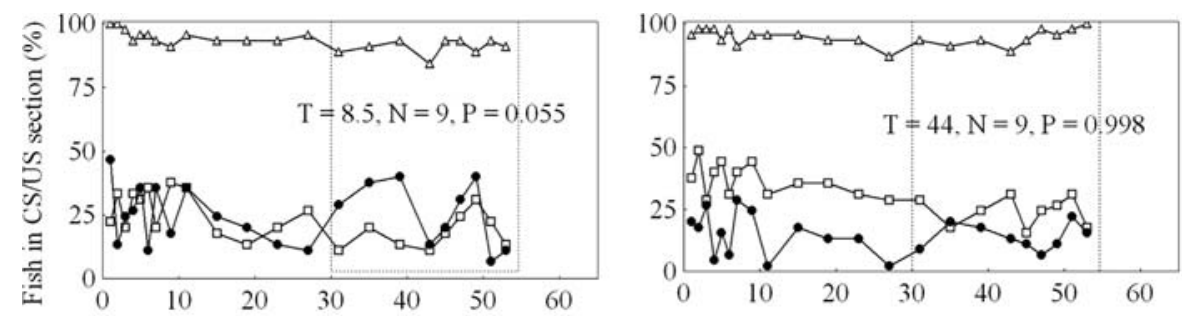

Control
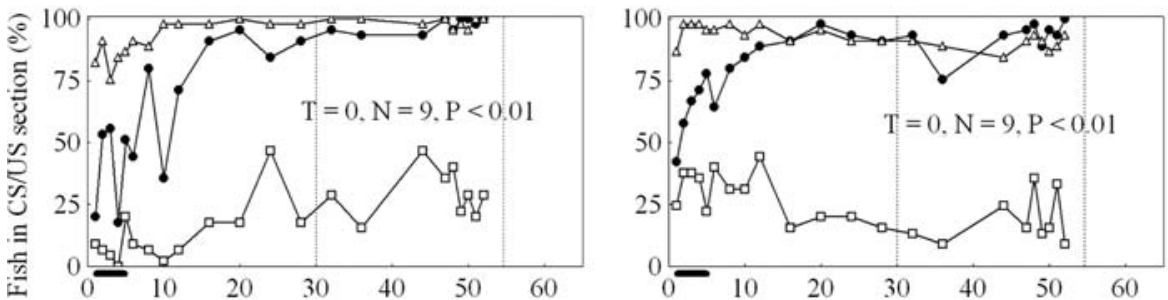

Delay
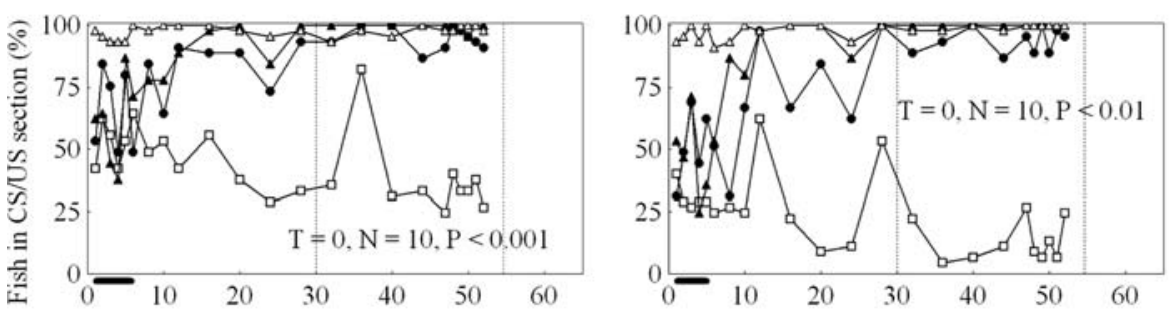

$\mathrm{T}_{20}$
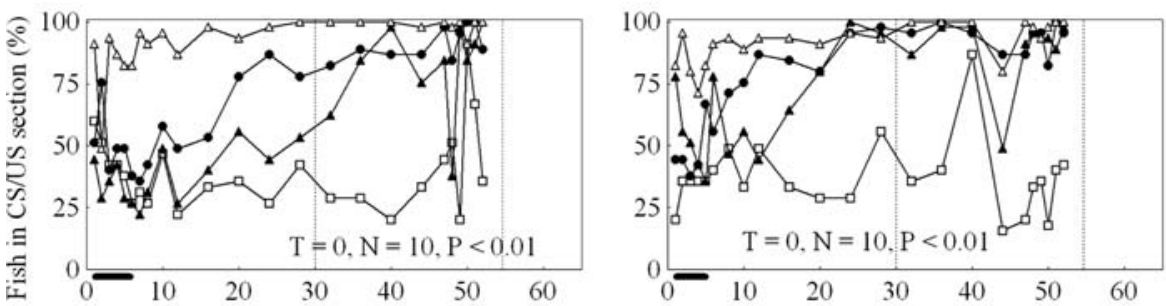

$\mathrm{T}_{60}$
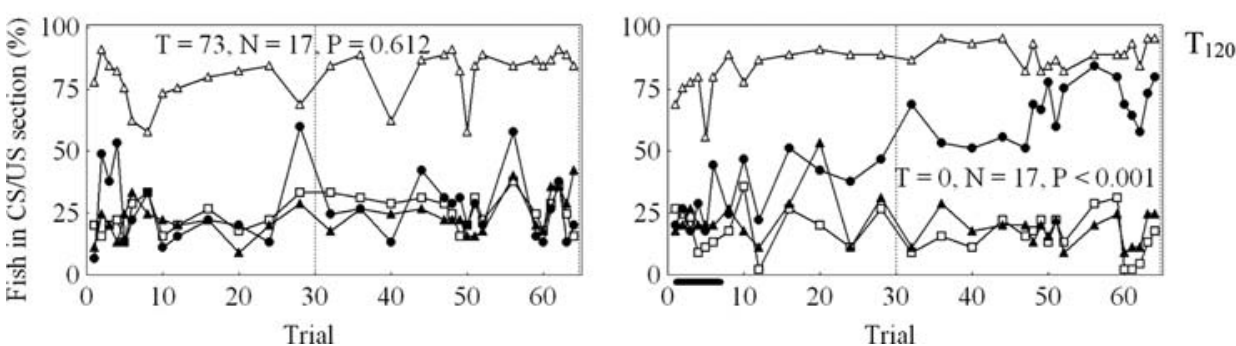
that included all analysed trials from trial 30 onwards. Onetailed tests were justified by the assumption that an association between the CS and the rewarding US should not result in an avoidance of the CS, i.e. a reduction of fish in the CS/ US section during CS presentation. In order to estimate the maximum number of trials needed for the fish to respond to the CS (i.e. number of fish in the CS/US section is higher during the CS than before CS onset), we performed a onetailed Wilcoxon signed rank test of the early trials that initially included trials 2-6 (trial 2 is the first trial in which a CS response can be attributed to an association with the US, and five trials are the minimum needed to obtain significance at the 0.05 level). If no difference was found, the following trial was included until there was a significant difference. One-tailed Wilcoxon signed rank test was also used on all memory trials. As the main question in this study was whether cod have the capacity to associate a light signal with a reward with the given interstimulus and trace intervals, statistical tests were performed separately for each tank in order to avoid the possibility that failure of conditioning in some groups would mask success in other groups. No statistical comparisons were made between groups.

\section{Results}

\section{Conditioning experiment}

The response to the food (US) was high in all groups, with the mean percentage of fish occupying the CS/US section during the US ranging from $81-98 \%$ (Fig. 2), and almost all fish engaged in feeding. In the unpaired control groups, the number of fish in the CS/US section did not increase during the CS (Fig. 2). In the delay, $\mathrm{T}_{20}, \mathrm{~T}_{60}$ and one of the $\mathrm{T}_{120}$ groups (replicate 2 ) more fish occupied the CS/US section during the CS than before CS onset in all analysed tri- als after trial 30 (Fig. 2). In the other $\mathrm{T}_{120}$ group (replicate 1 ), the number of fish in the CS/US section did not increase during the CS (Fig. 2). The groups that were conditioned at the end of the experiment started to respond to the CS after a few trials, with a significant response to the CS within six to eight trials (Fig. 2).

Fish in the $\mathrm{T}_{20}$ groups approaching the CS/US section during the CS remained there, staying under or close to the light ring during the trace interval, waiting for the food to arrive (Fig. 2). The $\mathrm{T}_{60}$ groups left the CS/US section during the trace interval in the first trials after responding to the CS, but remained in the CS/US section during the trace interval in the later trials (Fig. 2). The $\mathrm{T}_{120}$ groups did not remain in the CS/US section during the trace interval (Fig. 2). The conditioned delay, $\mathrm{T}_{20}$ and $\mathrm{T}_{60}$ groups, but not the $\mathrm{T}_{120}$ groups, displayed hyperactive behaviour with for instance rapid body movements and crowding below the feeder during the interstimulus interval.

\section{Memory test}

For all groups in the memory test, both the delay groups (88 days after conditioning) and the $20 \mathrm{~s}$ trace groups (70 days after conditioning), number of fish in the CS section increased at CS onset in all trials (one-tailed Wilcoxon signed rank test; for all groups, $T=0, N=6, P<0.05$, Fig. 3).

\section{Discussion}

This study has demonstrated that socially living Atlantic cod reliably can associate events that occur with a time gap of up to at least $60 \mathrm{~s}$. Furthermore, they remember such associations for at least 3 months. These findings demonstrate that the learning capacities of fish are far more sophisticated than has been appreciated until now.
Fig. 3 Percentage of fish in the CS section of the tank before CS onset (baseline, squares) and during the CS (circles) a 88 days after end of delay conditioning and $\mathbf{b} 70$ days after end of $20 \mathrm{~s}$ trace conditioning. Left and right figures are replicate groups
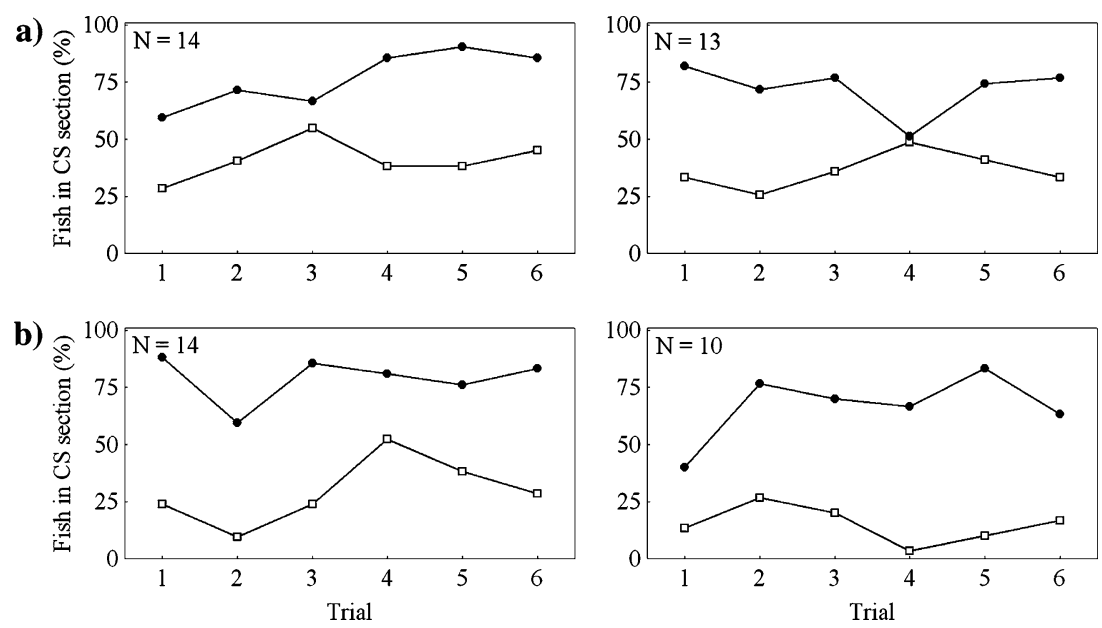
Sudden changes in light levels could be aversive to fish (Lines and Frost 1999), and startle responses at the onset of the light signal were observed in three groups in the first trials. Still, the fish responded positively to the light signal after few trials when it was paired with food. When the delay, $\mathrm{T}_{20}$ and $\mathrm{T}_{60}$ groups had become conditioned they displayed anticipatory behaviour during the interstimulus interval, such as crowding in the CS/US area during CS presentation and, for the trace groups, throughout the trace interval. In the one $\mathrm{T}_{120}$ group that responded positively to the CS, the fish did not remain in the CS/US area during the trace interval, nor did they become hyperactive. Furthermore, this response to the $\mathrm{CS}$ could not be replicated in the other $\mathrm{T}_{120}$ group. This indicates that a $120 \mathrm{~s}$ trace interval is close to the upper limit that allows an association to be established in cod.

In all the conditioned groups a CS-US association was established after a maximum of five to seven trials and probably, though this was not possible to prove statistically with our experimental design, even faster, at least in the delay groups (Fig. 2). The CS response reached a plateau at about 15 trials in the delay and 25 trials in the $\mathrm{T}_{60}$ experiments, which must be regarded as rapid learning (Lieberman 2000). Comparing the learning capacities of cod demonstrated here with previous studies on other species should be made carefully, as most studies have used different procedures and shorter intertrial intervals, which may influence the trace interval tolerated and number of trials required to obtain conditioned responses (Newlin and LoLordo 1976; Holland 2000). Still, it is noteworthy that in autoshaping procedures with pigeons (Columba livia), considerably more trials are required to obtain conditioned responses. In delay conditioning with a short interstimulus interval pigeons started to respond to the CS key light after 10-20 trials (Brown and Jenkins 1968; Newlin and LoLordo 1976), while with a $8 \mathrm{~s}$ trace interval robust acquisition was achieved after a median of 566 trials (Balsam and Gibbon 1982), and with a 24 s trace interval weak and sporadic responses developed at about 1,500 trials (Newlin and LoLordo 1976). With a strong aversive US, mice (Mus domesticus) responded to the CS after one trial when the trace interval was $30 \mathrm{~s}$, but not $45 \mathrm{~s}$ (Misane et al. 2005).

Whereas most conditioning experiments train individual subjects, we trained groups of fish, and social learning may have speeded up the learning process. Individuals that followed other individuals who responded to the CS may have detected the CS-US relationship by means of observational conditioning (Brown and Laland 2006). An additional effect of group training may be that the response of other individuals acts as an additional CS. Some fish may have learnt an association between the approach of other individuals to the feeding area and the following US, rather than an association between the light signal and the US. As the light signal and the response of other individuals occurred more or less simultaneously, the CS (light) may have been blocked by the other fishes' behaviour (Lieberman 2000). As we measured the response to the CS in terms of the proportion of fish gathering at the CS/US area, it is not possible to tell how many fish actually learnt the CS-US relationship, and how many followed other individuals without knowledge about the forthcoming reward. Still, at least one individual in each of the conditioned group must have learnt the relationship, demonstrating that cod have the potential to associate events temporarily separated on a scale of minutes. Social learning and/or following of other individuals as explanations of the group response during the CS are especially probable when the fish had the most difficult tasks. It is unlikely that many individuals in the one $\mathrm{T}_{120}$ group detected the relationship independently, when no fish did so in the other $\mathrm{T}_{120}$ group. Behavioural copying and social learning play an important role in foraging and antipredator behaviour in social fish species (Pitcher and Parrish 1993; Brown and Laland 2003), and group responses are the most relevant situation for learning in social species both in the wild and in aquaculture (Pitcher and Parrish 1993; Fernö et al. 2006).

In order to categorize the environment into concepts of more or less significance for fitness, it is crucial to have the ability to learn associations between events. If an event is followed by a reward, the fish will get a hint of the coming reward at their next encounter with a similar event and their probability of responding correctly will increase. This is not only true for events that come immediately before the reward, e.g. the sight of a prey and food, but also for events that signal that a reward is expected in the near future, like the sound of a hidden prey. The capacity of cod to associate events even when there is a considerable time gap between them should give cod a good ability to "read" their environment through cue signals, and to easily adapt to new situations during changes in life stages and migrations to other habitats. Events may concur rarely, and if the cost of responding incorrectly to a stimulus is high (death or injury), associations may be learnt after one trial (Beukema 1970; Fernö and Huse 1983) and remembered for more than a year (Beukema 1970). To the best of our knowledge, no previous studies have investigated the long-term storage of reward-associated memories in fish. The cod in the present study retained the CS-US association for months, regardless of whether they were trained in a delay or trace protocol. Even though an incorrect response to a reward is usually non-critical for survival, the ecological significance of longtime persistence of reward-associated memories may be high. Events that involve increased food availability may be frequent and important in some periods but absent in others, for instance rag worm swarming or moulting in crabs. The ability to remember cues for such events should maintain improved behaviour from one season to another. 
To learn an association between stimuli separated by a temporal gap, i.e. trace conditioning, is more cognitively demanding than when stimuli overlap in time, i.e. delay conditioning (Lieberman 2000). In mammals trace conditioning is critically dependent on the hippocampus, while this is not the case for delay conditioning (Solomon et al. 1986). Similarly, in teleosts trace conditioning, but not delay conditioning, is dependent on the lateral pallium, a homologous (Braford 1995; Butler 2000) and functional (Portavella et al. 2002, 2004) equivalent to the hippocampus. This suggests that in teleosts, like in mammals, delay and trace conditioning involve two separate memory systems (Broglio et al. 2005), and these systems seem to have emerged early in the phylogenetic history of vertebrates (Rodriguez et al. 2006). In humans declarative memory is highly dependent on the hippocampus, and in trace eyeblink conditioning an awareness of the CS-US relationship is a prerequisite for the acquisition of conditioned responses (Clark and Squire 1998). It is interesting that fish can learn an association between a CS and a US separated by a temporal gap, both when the US is aversive (Álvarez et al. 2003) and rewarding (present study), tasks that in many respects are similar to trace eye-blink conditioning, that in human is dependent on awareness (Clark and Squire 1998). In the 20 and $60 \mathrm{~s}$ trace procedures in the present study, the fish did not only respond during the CS presentation, but kept their anticipatory behaviour (crowding below the feeder waiting for food to arrive) throughout the trace interval. This behaviour suggests that they had some representation about the forthcoming reward. Taking into account the similarities of the memory systems of teleosts and mammals and the role of awareness in human trace conditioning, we interpret the strong anticipatory behaviour of the cod throughout the long trace intervals as reflecting some form of awareness of the CS predicting the US. A review by Chandroo et al. (2004) suggests that fish are more likely to be sentient than not, and our results support this.

In conclusion, we have demonstrated that in an appetitive Pavlovian conditioning paradigm cod have the potential to rapidly associate stimuli that are separated with a time gap of at least $1 \mathrm{~min}$, which is indicative of awareness. Once associations are learnt, they can be remembered for at least 3 months.

Acknowledgments We would like to thank Victoria Braithwaite and three anonymous referees for comments on an earlier version of the manuscript. This research was funded by the Research Council of Norway, and complies with the Norwegian regulation on animal experimentation.

\section{References}

Álvarez E, Gómez A, Durán E, Ocaña FM, Jimenez-Moya F, Broglio C, Rodriguez F, Salas C (2003) Brain substrates of 'eyeblink' classical conditioning in goldfish. Acta Neurobiol Exp 63(Suppl):62

Balsam PD, Gibbon J (1982) Factors underlying trace decrements in autoshaping. Behav Anal Lett 2:197-204

Beukema JJ (1970) Angling experiments with carp (Cyprinus carpio L.) II. Decreasing catchability through one-trial learning. Neth J Zool 20:81-92

Braford MR (1995) Comparative aspects of forebrain organization in the ray-finned fishes: touchstones or not? Brain Behav Evol 46:259-274

Broglio C, Gomez A, Duran E, Ocaña FM, Jimenez-Moya F, Rodriguez F, Salas C (2005) Hallmarks of a common forebrain vertebrate plan: specialized pallial areas for spatial, temporal and emotional memory in actinopterygian fish. Brain Res Bull 66:277-281. doi: 10.1016/j.brainresbull.2005.03.021

Brown C (2001) Familiarity with the test environment improves escape responses in the crimson spotted rainbowfish, Melanotaenia duboulayi. Anim Cogn 4:109-113 doi:10.1007/s100710100105

Brown C, Laland KN (2003) Social learning in fishes: a review. Fish Fish 4:280-288 doi: 10.1046/j.1467-2979.2003.00122.x

Brown C, Braithwaite VA (2005) Effects of predation pressure on the cognitive ability of the poeciliid Brachyraphis episcopi. Behav Ecol 16:482-487 doi: 10.1093/beheco/ari016

Brown C, Laland K (2006) Social learning in fishes. In: Brown C, Laland $\mathrm{K}$, Krause $\mathrm{J}$ (eds) Fish cognition and behavior. Blackwell, Oxford, pp 186-202

Brown C, Laland KN, Krause J (2006) Fish cognition and behaviour. Blackwell, Oxford

Brown PL, Jenkins HM (1968) Auto-shaping of pigeon's key-peck. J Exp Anal Behav 11:1-8 doi:10.1901/jeab.1968.11-1

Bull HO (1928) Studies on conditioned responses in fishes. J Mar Biol Assoc UK 15:485-533

Butler AB (2000) Topography and topology of the teleost telencephalon: a paradox resolved. Neurosci Lett 293:95-98 doi:10.1016/ S0304-3940(00)01497-X

Chandroo KP, Duncan IJH, Moccia RD (2004) Can fish suffer? perspectives on sentience, pain, fear and stress. Appl Anim Behav Sci 86:225-250 doi:10.1016/j.applanim.2004.02.004

Chapman CJ, Hawkins AD (1973) A field study of hearing in the cod, Gadus morhua L. J Comp Physiol 85:147-167 doi:10.1007/ BF00696473

Clark RE, Squire LR (1998) Classical conditioning and brain systems: the role of awareness. Science 280:77-81 DOI 10.1126/science. 280.5360 .77

Csányi V, Csizmadia G, Miklosi A (1989) Long-term memory and recognition of another species in the paradise fish. Anim Behav 37:908-911doi:10.1016/0003-3472(89)90134-6

Dahle G, Jørstad KE, Rusaas HE, Otterå H (2006) Genetic characteristics of broodstock collected from four Norwegian coastal cod (Gadus morhua) populations. ICES J Mar Sci 63:209-215 doi:10.1016/j.icesjms.2005.10.015

Dell MB (1968) A new fish tag and rapid cartridge-fed applicator. T Am Fish Soc 97:57-59 doi:10.1577/15488659(1968)97[57:ANFTAR]2.0.CO;2

Fernö A, Huse I (1983) The effect of experience on the behavior of cod (Gadus morhua L.) towards a baited hook. Fish Res 2:19-28 doi:10.1016/0165-7836(83)90100-5

Fernö A, Huse G, Jakobsen PJ, Kristiansen TS (2006) The role of fish learning skills in fisheries and aquaculture. In: Brown C, Laland K, Krause J (eds) Fish cognition and behavior. Blackwell, Oxford, pp 278-310

Holland PC (2000) Trial and intertrial durations in appetitive conditioning in rats. Anim Learn Behav 28:121-135

Kelley JL, Magurran AE (2003) Learned predator recognition and antipredator responses in fishes. Fish Fish 4:216-226 doi:10.1046/ j.1467-2979.2003.00126.x 
Laland KN, Brown C, Krause J (2003) Learning in fishes: from threesecond memory to culture. Fish Fish 4:199-202 doi:10.1046/ j.1467-2979.2003.00124.x

Lieberman DA (2000) Learning: behavior and cognition. Wadsworth, Belmont

Lines JA, Frost AR (1999) Review of opportunities for low stress and selective control of fish. Aquacult Eng 20:211-230 doi:10.1016/ S0144-8609(99)00016-3

MacKay B (1974) Conditioned food aversion produced by toxicosis in Atlantic cod. Behav Biol 12:347-355 doi:10.1016/S00916773(74)91531-4

Mackney PA, Hughes RN (1995) Foraging behaviour and memory window in sticklebacks. Behaviour 132:1241-1253

Midling KØ, Kristiansen T, Ona E, Øiestad V (1987) Fjordranching with conditioned cod. Count Meet Int Count Explor Sea F:29:111

Misane I, Tovote P, Meyer M, Spiess J, Ögren SO, Stiedl O (2005) Time-dependent involvement of the dorsal hippocampus in trace fear conditioning in mice. Hippocampus 15:418-426 doi:10.1002/hipo.20067

Newlin RJ, LoLordo VM (1976) Comparison of pecking generated by serial, delay, and trace autoshaping procedures. J Exp Anal Behav 25:227-241 doi:10.1901/jeab.1976.25-227

Odling-Smee L, Braithwaite VA (2003) The role of learning in fish orientation. Fish Fish 4:235-246 doi:10.1046/j.14672979.2003.00127.x

Otterå H, Kristiansen TS, Svåsand T (1998) Evaluation of anchor tags used in sea-ranching experiments with Atlantic cod (Gadus morhua L.). Fish Res 35:237-246 doi:10.1016/S01657836(97)00055-6

Overmier JB, Savage GE (1974) Effects of telencephalic ablation on trace classical conditioning of heart rate in goldfish. Exp Neurol 42:339-346 doi:10.1016/0014-4886(74)90031-4

Overmier J, Hollis K (1990) Fish in the think tank: learning, memory, and integrated behavior. In: Kesner R, Olton D (eds) Neurobiology of comparative cognition. Lawrence Erlbaum, Hillsdale, pp 205-236
Pitcher TJ, Parrish JK (1993) Functions of shoaling behaviour in teleosts. In: Pitcher TJ (ed) Behaviour of teleost fishes. Chapman \& Hall, London, pp 363-439

Portavella M, Vargas JP, Torres B, Salas C (2002) The effects of telencephalic pallial lesions on spatial, temporal, and emotional learning in goldfish. Brain Res Bull 57:397-399 doi:10.1016/S03619230(01)00699-2

Portavella M, Torres B, Salas C (2004) Avoidance response in goldfish: emotional and temporal involvement of medial and lateral telencephalic pallium. J Neurosci 24:2335-2342 doi:10.1523/ JNEUROSCI.4930-03.2004

Rodriguez F, Broglio C, Durán E, Gómez A, Salas C (2006) Neural mechanisms of learning in teleost fish. In: Brown C, Laland $\mathrm{K}$, Krause J (eds) Fish cognition and behavior. Blackwell, Oxford, pp 243-277

Solomon PR, Vander Schaaf ER, Thompson RF, Weisz DJ (1986) Hippocampus and trace conditioning of the rabbit's classically-conditioned nictitating-membrane response. Behav Neurosci 100:729-744

Sovrano VA, Rainoldi C, Bisazza A, Vallortigara G (1999) Roots of brain specializations: preferential left-eye use during mirror-image inspection in six species of teleost fish. Behav Brain Res 106:175-180 doi:10.1016/S0166-4328(99)00105-9

Sovrano VA, Bisazza A, Vallortigara G (2002) Modularity and spatial reorientation in a simple mind: encoding of geometric and nongeometric properties of a spatial environment by fish. Cognition 85:B51-B59 doi:10.1016/S0010-0277(02)00110-5

Sovrano VA, Bisazza A, Vallortigara G (2007) How fish do geometry in large and in small spaces. Anim Cogn 10:47-54 doi:10.1007/ s10071-006-0029-4

Thompson RF, Kim JJ (1996) Memory systems in the brain and localization of a memory. Proc Natl Acad Sci USA 93:13438-13444

Vallortigara G, Rogers LJ (2005) Survival with an asymmetrical brain: advantages and disadvantages of cerebral lateralization. Behav Brain Sci 28:575-589 doi:10.1017/S0140525X05000105

Warburton K (2003) Learning of foraging skills by fish. Fish Fish 4:203-215 DOI 10.1046/j.1467-2979.2003.00125.x 